\title{
Statewide Breastfeeding Hotline Use Among Tennessee WIC Participants
}

\author{
Sierra M. Mullen, $\mathrm{MPH}^{1}$; August Marshall, $\mathrm{MA}^{2}$; Michael D. Warren, MD, $\mathrm{MPH}^{1}$
}

\begin{abstract}
Objective: To examine the use of the Tennessee Breastfeeding Hotline (TBH), a 24 h/d, 7-d/wk telephonic lactation support program, based on Special Supplemental Nutrition Program for Women, Infants, and Children (WIC) participation.

Methods: Self-reported quantitative data were collected during the initial call. Data collected included caller type, maternal and infant characteristics, breastfeeding (BF) status, and primary reason for contacting the TBH.

Results: A total of 366 participants in WIC and 1,354 participants not enrolled in WIC received services through the TBH. Significant differences existed for maternal age, race, ethnicity, infant age, preterm delivery, caller type, and exclusive $\mathrm{BF}(P<.05)$. Among participants in WIC, lactation professionals primarily addressed concerns related to lactation and milk expression.

Conclusions and Implications: The $\mathrm{TBH}$ is a resource to address BF concerns, particularly among women who may face barriers to seeking professional lactation advice. Special Supplemental Nutrition Program for Women, Infants, and Children agencies might consider implementing initiatives outside their standard scope of clinic practice to address participants' needs for BF support.

Key Words: WIC, breastfeeding, telephone hotline, lactation support (J Nutr Educ Behav. 2017;49: S192-S196.)
\end{abstract}

Accepted April 27, 2017.

\section{INTRODUCTION}

The advantages of breastfeeding (BF) are well documented; it offers numerous nutritional and health benefits for mothers and children. ${ }^{1}$ According to the 2015 National Immunization Survey, $74.1 \%$ of women receiving services from the Special Supplemental Nutrition Program for Women, Infants, and Children (WIC) initiated BF, compared with $82 \%$ of eligible women not enrolled in WIC and $91.1 \%$ of women ineligible for WIC. At 6 months, 39.1\% of participants in WIC were BF, compared with
$60.9 \%$ and $68.6 \%$ of eligible women not enrolled in WIC and women ineligible for WIC, respectively. ${ }^{2}$ Despite various $\mathrm{BF}$ promotion efforts within WIC, disparities persist between program participants and the general population. BF rates among women enrolled in WIC continue to fall below general population estimates and the Healthy People 2020 target. $^{3}$

Tennessee BF rates are historically lower than national rates. In 2013, $71.1 \%$ of Tennessee infants had ever been breastfed. ${ }^{2}$ Similar to national patterns, BF rates were lower among

\footnotetext{
${ }^{1}$ Division of Family Health and Wellness, Tennessee Department of Health, Nashville, TN ${ }^{2}$ Department of Community Health and Well-Being, Le Bonheur Children's Hospital, Memphis, TN

Conflict of Interest Disclosure: The authors' conflict of interest disclosures can be found online with this article on www.jneb.org.

Address for correspondence: Sierra M. Mullen, MPH, Tennessee Department of Health, Division of Family Health and Wellness, Andrew Johnson Tower, 8th Fl, 710 James Robertson Pkwy, Nashville, TN 37243; Phone: (615) 253-7280; Fax: (615) 532-7189; E-mail: sierra. mullen@tn.gov

(C2017 Society for Nutrition Education and Behavior. Published by Elsevier, Inc. All rights reserved.

the state's participants in WIC. The WIC Participant and Program Characteristics 2014 Report estimated that $50.2 \%$ of Tennessee infants and children had ever been breastfed; nearly a quarter $(24.8 \%)$ had breastfed for $\geq 6$ months. ${ }^{4}$

A meta-analysis examining BF among the population enrolled in WIC found that barriers included lack of support and education during the perinatal period, returning to work, breast and lactation concerns, formula promotion, and social or cultural barriers. ${ }^{5}$ Also, limited knowledge about $\mathrm{BF}$ and environmental support were found to shorten BF duration among participants in WIC. Another study examining infant feeding decisions among low-income families enrolled in the WIC program identified the decreased availability of help after hospital discharge as a major barrier to continuing BF. ${ }^{6}$ Factors associated with continuing BF included maternal age, education, beliefs about BF, public $\mathrm{BF}$, having been breastfed as child, provider influence, strong social networks, and employment status. ${ }^{6,7}$

There have been both federal and state initiatives to promote BF. In 
1997, the US Department of Agriculture's Food and Nutrition Service implemented the Loving Support Campaign within each WIC state agency to promote BF and peer counselor use, which was shown to increase BF initiation and duration. Tennessee used the Loving Support curriculum to train staff and peer counselors; it influenced the development of the BF support program. This model served as an evidencebased guide for best practices in peer counselor programs and provided a framework for policy development and BF training statewide.

Tennessee has implemented multiple local-level initiatives to improve BF promotion and support. Recent efforts included media campaigns targeting counties with lower initiation rates, recognition of BF-friendly businesses, lactation education for health professionals, baby-friendly hospital initiatives, and the assignment of a designated BF expert within all 115 regional and local health departments. In particular, the launch of the Tennessee Breastfeeding Hotline (TBH) provided all families with extra BF support and aimed to create equitable access to lactation advice, particularly for rural communities.

\section{Tennessee Breastfeeding Hotline Operations}

In November 2013, the Tennessee Department of Health implemented the $\mathrm{TBH}$, a free telephonic BF support program available to nursing mothers and partners, their families, expectant mothers, and health care providers. Promoted by numerous maternal and child health stakeholders, the TBH is a statewide resource offering accurate information for common BF issues. Callers speak with a Certified Lactation Counselor or an International Board Certified Lactation Consultant, who offers individualized advice and encouragement and refers callers to local resources when appropriate. If the caller's concern is beyond the scope of the lactation professional's expertise, staff notify the hotline's medical consultant, and subsequent referrals are made if needed. To ensure consistency, all lactation professionals use the American Academy of Pediatrics Breastfeeding Telephone Triage and Advice ${ }^{8}$ as their primary resource.
The TBH is jointly funded by WIC and the Title V Maternal and Child Health Services Block Grant and operates via contract from Le Bonheur Children's Hospital, Memphis, TN. The hotline is available $24 \mathrm{~h} / \mathrm{d}, 7 \mathrm{~d} / \mathrm{wk}$ and has access to interpretive services for $>200$ languages. To ensure timely receipt of service, the $\mathrm{TBH}$ strives to answer all calls immediately or returns calls within 30 minutes if staff is busy with other callers. Its structure is unique in operations, staffing, and methods of follow-up. With consent, staff contacts callers monthly for 3 months after the initial call to offer additional assistance, assess BF status, encourage BF continuation, and determine satisfaction of the services provided. To the best of the authors' knowledge, the TBH is the only statelevel $\mathrm{BF}$ hotline that conducts this type of follow-up with callers.

Through collaborative efforts, Tennessee WIC allocated its funding differently to develop an innovative program for optimal BF practices. Telephonic support provides an inexpensive and replicable way for mothers to access lactation services; yet its effectiveness for participants in WIC is not well documented in the literature. One study concluded that BF duration among participants in WIC increased with the use of a telephone peer counseling program compared with standard WIC support for BF. ${ }^{9}$ No studies examined BF hotlines staffed by lactation professionals, but 1 systematic review suggested that interventions involving lactation consultants and counselors could improve postpartum BF rates. ${ }^{10}$ The objectives of this study were to describe callers to the $\mathrm{TBH}$, determine whether there were differences in the characteristics of callers from $\mathrm{TBH}$ who were enrolled or not in WIC, and compare the needs for postpartum BF support between participants who were enrolled in WIC and those who were not.

\section{METHODS}

Initial calls to the hotline were routed through OneBox (j2 Global Inc., Los Angeles, CA), an automated phone routing system. A prerecorded greeting in both English and Spanish queued callers for an available lactation professional or callers left a voice mail. All data were entered into iCarol (CharityLogic Corporation, Fairfax, CA), a secure helpline software system that allowed TBH staff to submit call reports, conduct follow-up calls or texts, and maintain a BF resource directory. During the initial call, the lactation professionals gathered data including call characteristics, caller and infant demographics, primary reason for calling, referral source, referrals made to the caller, and immediate outcomes. The Tennessee Department of Health Institutional Review Board determined this project to be exempt from review based on the use of existing data to evaluate a public benefit or service program.

Study analyses included data since October 2015, when a question was added to capture use of the TBH for participants who were enrolled in WIC. Characteristics of individuals who answered yes to the question Are you currently receiving WIC services? were compared with calls that answered no to the question. Analyses were restricted to mothers who resided in Tennessee with documented participation in WIC. The TBH collected no other form of information on income (eg, amount of income earned, participation in the Supplemental Nutrition Assistance Program, Medicaid recipient) besides receiving WIC services. The researchers used descriptive statistics to examine caller demographics and characteristics, overall and by WIC participation. Chi-square test of homogeneity was used to compare proportions between the 2 subgroups. All analyses were conducted using SAS (version 9.4, SAS Institute, Cary, NC, 2013). Statistical significance was set at $P<.05$.

\section{RESULTS}

Between October 2015 and September 2016, the $\mathrm{TBH}$ received 5,907 calls. Calls from out-of-state residents $(\mathrm{n}=875)$ and those from individuals other than the mother $(n=412)$ were excluded. Calls with missing WIC status $(\mathrm{n}=2,900)$ were also excluded. This resulted in 1,720 calls with documented WIC status for inclusion in the final analyses: 366 who participated in WIC and 1,354 who did not. Table 1 lists characteristics of those mothers. Compared with calls from mothers who were not enrolled in 
Table 1. Demographic and Call Characteristics of Mothers Provided Tennessee Breastfeeding Hotline Services, by Participation in WIC

\begin{tabular}{|c|c|c|c|c|}
\hline Characteristic & $\begin{array}{c}\text { Overall } \\
(\mathbf{N}=1,720)\end{array}$ & $\begin{array}{c}\text { Participant } \\
\text { in WIC }(n=366)\end{array}$ & $\begin{array}{c}\text { Participant Not } \\
\text { in WIC }(n=1,354)\end{array}$ & $\boldsymbol{P}^{*}$ \\
\hline $\begin{array}{l}\text { Geographic type } \\
\text { Metro } \\
\text { Rural }\end{array}$ & $\begin{array}{l}56.4 \\
43.6\end{array}$ & $\begin{array}{l}53.4 \\
46.6\end{array}$ & $\begin{array}{l}57.3 \\
42.7\end{array}$ & .19 \\
\hline $\begin{array}{l}\text { Maternal age, y } \\
\quad \leq 20 \\
21-30 \\
31-40 \\
>40\end{array}$ & $\begin{array}{r}4.2 \\
62.2 \\
32.4 \\
1.2\end{array}$ & $\begin{array}{r}14.7 \\
65.2 \\
19.0 \\
1.1\end{array}$ & $\begin{array}{r}1.2 \\
61.3 \\
36.3 \\
1.2\end{array}$ & $<.001$ \\
\hline $\begin{array}{l}\text { Race } \\
\text { White } \\
\text { Black } \\
\text { Other }\end{array}$ & $\begin{array}{r}75.4 \\
18.2 \\
6.3\end{array}$ & $\begin{array}{r}57.5 \\
34.1 \\
8.4\end{array}$ & $\begin{array}{r}80.5 \\
13.7 \\
5.8\end{array}$ & $<.001$ \\
\hline $\begin{array}{l}\text { Ethnicity } \\
\text { Hispanic } \\
\text { Non-Hispanic }\end{array}$ & $\begin{array}{r}5.0 \\
95.0\end{array}$ & $\begin{array}{r}7.3 \\
92.7\end{array}$ & $\begin{array}{r}4.4 \\
95.6\end{array}$ & .02 \\
\hline $\begin{array}{l}\text { Caller type } \\
\text { First time } \\
\text { Repeat }\end{array}$ & $\begin{array}{l}72.4 \\
27.6\end{array}$ & $\begin{array}{l}83.9 \\
16.1\end{array}$ & $\begin{array}{l}69.4 \\
30.6\end{array}$ & $<.001$ \\
\hline $\begin{array}{l}\text { Preterm delivery } \\
\text { Yes } \\
\text { No }\end{array}$ & $\begin{array}{r}6.8 \\
93.2\end{array}$ & $\begin{array}{l}10.8 \\
89.2\end{array}$ & $\begin{array}{r}5.7 \\
94.3\end{array}$ & $<.001$ \\
\hline $\begin{array}{l}\text { Infant age, mo } \\
\qquad 1 \\
\quad 1-5 \\
\quad \geq 6\end{array}$ & $\begin{array}{l}51.6 \\
36.9 \\
11.5\end{array}$ & $\begin{array}{r}51.3 \\
41.2 \\
7.5\end{array}$ & $\begin{array}{l}51.6 \\
35.7 \\
12.6\end{array}$ & .02 \\
\hline $\begin{array}{l}\text { Exclusively feeding } \\
\text { breast milk } \\
\text { Yes } \\
\text { No }\end{array}$ & $\begin{array}{l}77.4 \\
22.6\end{array}$ & $\begin{array}{l}65.6 \\
34.4\end{array}$ & $\begin{array}{l}81.7 \\
18.3\end{array}$ & $<.001$ \\
\hline
\end{tabular}

WIC indicates Special Supplemental Nutrition Program for Women, Infants, and Children.

*Statistical significance between participants enrolled or not in WIC, $P<.05$.

Notes: Chi-square for homogeneity was used for statistical analysis. Variables with missing data included geographic type (1.5\%), ethnicity $(3.7 \%)$, race $(5.5 \%)$, maternal age (7.3\%), gestational age at delivery (8.5\%), infant age (10.6\%), and breastfeeding status (36.9\%). Percentages may not sum to 100 owing to rounding.

WIC, participants in WIC were more likely to be younger $(P<.001)$, nonwhite $(P<.001)$, Hispanic $(P=.02)$, and a first-time caller $(P<.001)$; to have delivered preterm $(P<.001)$; to be nursing a younger infant $(P=.02)$; and to be nonexclusively feeding breast milk to their infant $(P<.001)$. Primary reasons for calling the hotline differed between calls from those who were and were not enrolled in WIC. The 46 individual reasons reported by callers were classified into 12 categories (Table 2), ranging from individual to environmental factors. Participants in
WIC were more likely to call with issues related to milk expression $(P=.02)$; supplemental nutrition $(P=.04)$; and lactation concerns such as not making enough milk, breast pumps and rentals, and milk storage $(P=.005)$. In comparison, more mothers who were not enrolled in WIC needed assistance addressing breast-related problems (eg, breast engorgement, breast or nipple pain) $(P=.005)$ and anxiety about the infant's health state while $\mathrm{BF}$, such as refusing to nurse and appropriate feeding by age and weight $(P=.03)$.

\section{DISCUSSION}

These results describe the use of a statewide telephonic lactation support program among Tennessee participants in WIC and add to a limited body of literature on the use of telephonic counseling for these participants. Call volume to the $\mathrm{TBH}$ has steadily increased since its inception, including callers from other states and territories. From November 2013 to September 2016 , the hotline received 13,509 calls and averaged about 400 calls monthly. In general, health care providers may lack time, be uncomfortable, or feel unprepared to deal with BF management. ${ }^{11,12}$ Staffed with certified lactation professionals, the TBH handled a wide range of $\mathrm{BF}$ issues a mother could encounter. Calls received from individuals enrolled in WIC appeared to be appropriate for telephonic counseling, because approximately $80 \%$ were handled without additional medical referral vs $87.7 \%$ of calls from those who did not participate in WIC (85.8\% overall). Furthermore, the hotline removed some of the financial, geographical, transportation, or language barriers that women who participated in WIC may have faced when seeking BF support. 5,7,9

The majority of calls from participants in WIC were from those with an increased risk for $\mathrm{BF}$ challenges. Participants in WIC used the TBH to address concerns related to $\mathrm{BF}$ initiation or establishment, whereas those who did not participate in WIC called about issues that impeded BF maintenance. Those challenges could cause a mother not to reach her BF goal, especially younger mothers. The reasons why participants in WIC called the TBH were consistent with prior literature that cited practical and perceived issues related to inadequate milk production as common barriers to $\mathrm{BF}$ continuation. $^{5-7}$ Personal perception of inadequate milk supply can interfere with confidence, ${ }^{11}$ which could have resulted in mothers who were enrolled in WIC accessing the services of $\mathrm{TBH}$ at an earlier stage of their BF journey, compared with mothers who were not enrolled in WIC.

A significantly higher proportion of participants in WIC called the TBH seeking help about supplemental feeding. This may have resulted from 
Table 2. Primary Reason for Mothers Calling Tennessee Breastfeeding Hotline, by Participation in WIC

\begin{tabular}{lccc} 
Reason for Call & $\begin{array}{c}\text { Participant } \\
\text { in WIC (n=366) }\end{array}$ & $\begin{array}{c}\text { Participant Not } \\
\text { in WIC (n= 1,354) }\end{array}$ & $\boldsymbol{P}^{\star}$ \\
\hline Breast problems & 17.4 & 24.5 & .005 \\
\hline Breastfeeding management & 3.4 & 6.0 & .06 \\
Breastfeeding support & 2.6 & 2.1 & .59 \\
\hline Breastfeeding technique & 4.9 & 5.7 & .55 \\
\hline Expressing milk & 8.6 & 5.1 & .02 \\
\hline Infant behavior or concerns & 17.7 & 23.0 & .03 \\
Infant medical condition & 1.1 & 0.7 & .49 \\
\hline Lactation concerns & 20.9 & 14.7 & .005 \\
\hline Maternal health behaviors & 16.9 & 14.7 & .32 \\
\hline Maternal health concerns & 2.9 & 2.1 & .40 \\
\hline Supplemental nutrition & 1.4 & 0.4 & .04 \\
\hline Other & 2.3 & 1.0 & .10 \\
\hline
\end{tabular}

WIC indicates Special Supplemental Nutrition Program for Women, Infants, and Children.

*Statistical significance between participants enrolled or not in WIC, $P<.05$.

Notes: Chi-square for homogeneity (or Fisher exact test) was used for statistical analysis. Reason for call was missing for $4.9 \%$ of callers. Percentages may not sum to 100 owing to rounding.

the structure of the WIC program and caller characteristics, because WIC's overall policies regarding infant formula were cited in prior literature as a barrier and may have undermined BF efforts. ${ }^{5,7,11}$ Also, 10.8\% of callers who were enrolled in WIC delivered a preterm infant, compared with $5.7 \%$ of callers who were not enrolled in the program $(P<.001)$, a circumstance that may have warranted an increased need for supplemental feeding. ${ }^{11}$ Finally, inquiries from callers enrolled in WIC about supplemental nutrition could have been about returning to work or school. However, the authors were unable to explore this further because information about education or employment status was not collected from callers.

This study had several limitations. A high amount of calls were missing WIC status $(>60 \%)$; therefore excluding these records may have led to biased estimates of characteristics and ultimately affected study results. Missing data resulted because WIC status was not a required question and because of the TBH's priority of service delivery vs data collection. In general, missing data for telephonic counseling programs are common. Issues of data collection and large amounts of mis- sing data were observed for other population-based help lines that provided public health services. ${ }^{13-15}$ Reasons for missing data in analyses of other hotlines included staff reluctance to ask questions, data entry error, and callers' refusal to provide requested information. ${ }^{13,14}$ Similar issues could have existed for the $\mathrm{TBH}$, potentially leading to measurement bias, because the amount of data collected during each call may have differed owing to time constraints, nonresponse from callers, or staff data collection skill level. Although the hotline conducted follow-up calls, the researchers were unable to link those results to initial call data owing to the system's infrastructure. Finally, these results may not be representative of the general population or that enrolled in WIC, because callers to TBH may have been inherently more motivated to breastfeed.

\section{IMPLICATIONS FOR RESEARCH AND PRACTICE}

Telephonic lactation support is a way to offer professional guidance, resources, and promote optimal BF practices efficiently and at minimal cost to families. The $\mathrm{TBH}$ has received calls from 45 other states, the District of Columbia, and Puerto Rico, which suggests the need for similar services in other states or regions. The hotline fields calls from high-risk mothers with concerns previously shown to affect BF among participants in WIC; therefore this support modality may be particularly appropriate for participants in WIC. This strategy to support BF also aligns with other WIC efforts, including the use of peer counselors, clinic-based counseling, and promotion services. Not all Tennessee WIC clinics have a BF peer counselor, so the TBH benefits mothers who lack direct access to a local resource. Many of the BF issues encountered can be addressed by lactation professionals via telephone, which would free up time for clinical staff and BF peer counselors to support in clinic more mothers.

In the future, Tennessee must consider efforts to ensure the hotline's appropriate balance between service delivery and data collection. The approach to date has been to focus on maximizing the provision of BF support rather than collecting data for evaluation; further research would benefit from additional or more robust data. Ways to improve data quality include enhanced training for lactation professionals to collect more caller information or modified questions on the data collection form. State and local WIC agencies must continue to think creatively to strengthen BF efforts, explore new funding mechanisms, and advance strategies to increase $\mathrm{BF}$ rates for program participants.

\section{ACKNOWLEDGMENTS}

This work was supported by the US Department of Agriculture, Food and Nutrition Service, through a WIC grant (175TN712W1003) administered by the Tennessee Department of Health and by Tennessee's Title V Maternal and Child Health Services Block Grant (B04MC29326) from the US Department of Health and Human Services, Division of Health Resources and Services Administration, Maternal and Child Health Bureau. The authors acknowledge the administrative support of Le Bonheur Children's Hospital, the Tennessee Breastfeeding Hotline staff, and the following individuals for their contributions to this project: Peggy Lewis, Laura Campbell, Julie Traylor, 
S196 Mullen et al

Sandra Madubuonwu, Helen Scott, Dr Christina Underhill, Dr Angela M. Miller, and Dr Morgan F. McDonald. Data within this brief are provided from the Tennessee Breastfeeding Hotline, Centers for Disease Control and Prevention's National Immunization Survey, and the WIC Participant and Program Characteristics Report.

\section{REFERENCES}

1. American Academy of Pediatrics. Breastfeeding and the use of human milk. Pediatrics. 2012;129:e827-e841.

2. Centers for Disease Control and Prevention. National Immunization Survey. http://www.cdc.gov/breastfeeding/data/ NIS_data/index.htm. Accessed November 17, 2016.

3. US Department of Health and Human Services. Healthy People 2020 topics and objectives: maternal, infant and child health. https://www.healthypeople.gov/ 2020/topics-objectives/topic/maternalinfant-and-child-health/objectives. Accessed November 17, 2016.
4. Thorn B, Tadler C, Huret N, et al WIC Participant and Program Characteristics 2014. Alexandria, VA: US Dept of Agriculture, Food and Nutrition Service; 2015.

5. Hedberg IC. Barriers to breastfeeding in the WIC population. MCN Am J Matern Child Nurs. 2013;38:244-249.

6. Oniwon O, Tender JA, He J, Voorhees E, Moon RY. Reasons for infant feeding decisions in low-income families in Washington, DC. J Hum Lact. 2016;32:704-710.

7. Dunn RL, Kalich KA, Fedrizzi R, Phillips S. Barriers and contributors to breastfeeding in WIC mothers: a social ecological perspective. Breastfeed Med. 2015;10:493-501.

8. Bunik M. Breastfeeding Telephone Triage and Advice. 2nd ed. Elk Grove Village, IL: American Academy of Pediatrics; 2015.

9. Reeder JA, Joyce T, Sibley K, Arnold D, Altindag $\mathrm{O}$. Telephone peer counseling of breastfeeding among WIC participants: a randomized controlled trial. Pediatrics. 2014;134:e700-e709.
10. Patel S, Patel S. The effectiveness of lactation consultants and lactation counselors on breastfeeding outcomes. J Hum Lact. 2016;32:530-541.

11. Sriraman NK, Kellams A. Breastfeeding: what are the barriers? Why women struggle to achieve their goals. J Womens Health. 2016;25:714-722.

12. Garner CD, Ratcliff SL, Thornburg LL, Wethington E, Howard CR, Rasmussen KM. Discontinuity of breastfeeding care: "There's no captain of the ship." Breastfeed Med. 2016;11:32-39.

13. Spittal MJ, Fedyszyn I, Middleton A, et al. Frequent callers to crisis helplines: who are they and why do they call? Aust N Z J Psychiatry. 2015;49: 54-64.

14. Van Horn J, Eisenberg M, Nicholls CM, et al. Stop it now! A pilot study into the limits and benefits of a free helpline preventing child sexual abuse. J Child Sex Abus. 2015;24:853-872.

15. Mushtaq N, Boeckman LM, Beebe LA. Predictors of smokeless tobacco cessation among telephone quitline participants. Am J Prev Med. 2015; 48:S54-S60. 


\section{CONFLICT OF INTEREST}

The authors have not stated any conflicts of interest. 